\title{
Adherence to hypertensive treatment among patients coming to rural health and training centre of a medical college: A cross sectional study
}

\author{
Kishore Yadav Jothula ${ }^{1}$, Abhishek $\mathbf{P}^{2, *}$, Praveena Ganapa ${ }^{3}$, Pramodh Reddy $\mathbf{P}^{4}$, Navya Krishna Naidu ${ }^{5}$ \\ ${ }^{\mathbf{1}}$ Associate Professor, ${ }^{\mathbf{2}, \mathbf{5}}$ Post graduate, ${ }^{\mathbf{3}}$ Assistant Professor, Dept. of Community Medicine, Kamineni Institute of Medical \\ Sciences, Narketpally, Telangana, India
}

*Corresponding Author:

Email: abhishek.pokkuluri@gmail.com

\begin{abstract}
Introduction: Aim of the study was to assess the extent of adherence to anti hypertensive medications and to assess various socio demographic and other risk factors influencing adherence among the hypertensive patients attending rural health centre in Telangana.

Materials and Method: Total of 170 hypertensive patients who have visited rural health centre between November 2017 to March 2018 were interviewed to assess the extent of adherence to anti hypertensive medications.

Result: $53 \%$ of study population were females and majority (36.4\%) belong to 56-65 years of age group.70\% of study population were illiterates and most $(64.2 \%)$ of the subjects belong to lower middle socio economic status. Majority (55.9\%) of study population has to travel $>0.5$ hour from the rural health centre. $50 \%$ of the patients showed high adherence. Females $(61.1 \%)$ were significantly more adherent to medication compared to males(37.5\%). High adherence was observed among housewives(70.6\%), lower class(57.1\%) and widowed(57.9\%), those who need to travel for <0.5hr. Study population with the comorbities $(56.5 \%)$ were more adherent. Persons with both familial history and no familiar history have same adherence

Conclusion: Only half of the study subjects were found to be adherent to their treatment. In the current study it was observed that sex, employment status, religion and distance from RHTC were significantly associated with the adherence to treatment. Study population with the comorbidties, with habits like smoking and tobacco chewing were more adherent.
\end{abstract}

Keywords: Adherence, Rural health centre, Medication, Co-morbidities, Time, Tobacco.

\section{Introduction}

Hypertension is an overwhelming global challenge which ranks third as a cause of disability adjusted life years. ${ }^{1}$ Hypertension is a major cause of cardiovascular and cerebrovascular diseases. ${ }^{2}$ According to WHO,CVDs take the life of 17.7 million people every year, that is $31 \%$ of all global deaths and $>75 \%$ of CVD deaths occur in low income and middle income countries. $^{3}$ According to The National Family Health Survey -4 the prevalence of hypertension in India higher in urban when compared to rural areas. Among women the prevalence was $8.8 \%$ while men $13.6 \% .^{4}$

Adherence is defined by WHO as "The extent to which a person's behavior- taking medication following a diet and/or executing lifestyle changes corresponds with agreed recommendations from a health care provider". ${ }^{1}$ Poor adherence leads to bad outcome of disease and wastage of healthcare resources. ${ }^{1}$ Poor adherence to anti-hypertensive therapy is one of the biggest obstacles in therapeutic control of high blood pressure. It also compromises the efforts of the health care system, policy makers and health care professionals in improving the health of populations. Failure to adhere causes medical and psychological complications of the disease, reduces patients' quality of life, and erodes public confidence in health systems. ${ }^{5}$

We undertook this study with the objective of studying the extent of adherence to anti hypertensive medications and to assess various socio demographic and other risk factors influencing adherence.

\section{Materials and Method}

Study design: Institutional based Cross sectional study. Study setting: Rural Health Training Centre (RHTC) of Kamineni institute of Medical Sciences, Telangana Study period: four months from November 2017 to March 2018.

Study population: All patients who were diagnosed with hypertension atleast 1 year back

Inclusion Criteria: subject should be residing in the rural field practice area for at least one year and they should be able to provide information about medications in use.

Exclusion Criteria: Those not giving consent and not willing to participate.

Sample size: A total of 210 patients had visited RHTC during the 4 months period and only 170 agreed to participate in the study.

Study tool: A pre tested semi structured questionnaire was used to collect the data. Adherence was assessed using Morisky Medication adherence Scale (MMAS) $-8^{6}$ which is a screening tool in identifying non adherent patients. It is an 8 part questionnaire with score from 0 to 8 . Score 0 is considered as high adherence, score 1-2 is considered medium adherence and score 3-8 based as low adherence.

Procedure of Data Collection: After obtaining informed consent from the study subjects and explaining them the importance of study, data was collected by administering questionnaire. 
Confidentiality regarding the participant response for the questions was ensured.

\section{Analysis of data}

Data was entered in Microsoft excel and analysis was done using SPSS statistical package version 22. Chi square test was used to calculate the significance.

\section{Result}

$53 \%$ of study population were females and majority $(36.4 \%)$ belong to 56-65 years of age group and were housewives (30\%). Majority (70\%) of study population were illiterates, belong to lower middle socio economic status $(64.2 \%)$, were married $(75.8 \%)$ and were hindus $(91.7 \%)$. Majority of study population has to travel $>0.5$ hour from the RHTC $(55.9 \%)$. (Table 1)

$50 \%$ of the patients showed high adherence and only $12.4 \%$ showed low adherence. (Table 2)

Females $(61.1 \%)$ were more adherent to medication compared to males $(37.5 \%)$ and this difference was statistically significant. Adherence was more among $56-65(54.8 \%)$ years of age group than other age groups and this difference was not statistically significant. (Table 3)

It was observed that housewives $(70.6 \%)$ were more adherent than other employment groups and the difference was statistically significant. Illiterates $(53.8 \%)$ were more adherent to the treatment compared to literates and the difference was not statistically significant. (Table 4)

Lower class $(57.1 \%)$ and widowed(57.9\%) people were more adherent compared to other groups and the differences was not statistically significant. (Table 5)

Hindus $(51.9 \%)$ were more adherent to the treatment than others and those who need to travel for $<0.5 \mathrm{hr}$ from RHTC $(54.7 \%)$ were more adherent than who need to travel $>0.5 \mathrm{hr}$ from RHTC. These differences were statistically significant. (Table 6)

Study population with the comorbities $(56.5 \%)$, with habits like smoking and tobacco chewing $(56.5 \%)$ were more adherent. People without alcohol consumption were more adherent $(50.4 \%)$ and persons with both familial history and no familial history have same adherence. These differences were statistically not significant. (Table 7)

Table 1: Socio Demographic Profile of study population $(n=170)$

\begin{tabular}{|c|c|c|c|}
\hline \multicolumn{2}{|c|}{ Variable } & Frequency & Percentage \\
\hline \multirow{2}{*}{ Sex } & Male & 80 & 47 \\
\hline & Female & 90 & 53 \\
\hline \multirow[t]{5}{*}{ Age (years) } & $35-45$ & 18 & 10.5 \\
\hline & $46-55$ & 31 & 18.2 \\
\hline & $56-65$ & 62 & 36.4 \\
\hline & $66-75$ & 41 & 24.4 \\
\hline & $>75$ & 18 & 10.5 \\
\hline \multirow{5}{*}{$\begin{array}{l}\text { Employment } \\
\text { Status }\end{array}$} & Government & 1 & 0.5 \\
\hline & Merchant & 38 & 22.3 \\
\hline & Housewife & 51 & 30 \\
\hline & Farmer & 40 & 23.6 \\
\hline & Retired & 40 & 23.6 \\
\hline \multirow[t]{2}{*}{ Education } & Illiterate & 119 & 70 \\
\hline & Literate & 51 & 30 \\
\hline \multirow{5}{*}{$\begin{array}{l}\text { Socio } \\
\text { Economic } \\
\text { Status }\end{array}$} & Upper & 0 & 0 \\
\hline & Upper middle & 3 & 1.7 \\
\hline & Middle & 16 & 9.4 \\
\hline & Lower middle & 109 & 64.2 \\
\hline & Lower & 42 & 24.7 \\
\hline \multirow[t]{4}{*}{ Marital Status } & Single & 3 & 1.7 \\
\hline & Married & 129 & 75.8 \\
\hline & Divorced & 0 & 0 \\
\hline & Widowed & 38 & 22.5 \\
\hline \multirow[t]{4}{*}{ Religion } & Hindu & 156 & 91.7 \\
\hline & Muslim & 12 & 7 \\
\hline & Christian & 2 & 1.3 \\
\hline & Others & 0 & 0 \\
\hline \multirow{2}{*}{$\begin{array}{l}\text { Time to reach } \\
\text { RHTC }\end{array}$} & $<0.5$ hour & 75 & 44.1 \\
\hline & $>0.5$ hour & 95 & 55.9 \\
\hline
\end{tabular}


Table 2: Distribution of study population according to the extent of adherence to antihypertensive medication $(\mathrm{n}=\mathbf{1 7 0})$

\begin{tabular}{|c|c|}
\hline Adherence & Number of study subjects (\%) \\
\hline High & $85(50)$ \\
\hline Medium & $64(37.6)$ \\
\hline Low & $21(12.4)$ \\
\hline Total & $170(100)$ \\
\hline
\end{tabular}

Table 3: Comparison of Age and Sex with extent of adherence ( $n=170)$

\begin{tabular}{|c|c|c|c|c|c|c|}
\hline \multicolumn{2}{|c|}{ Variable } & $\begin{array}{c}\text { High } \\
\text { adherence }\end{array}$ & $\begin{array}{c}\text { Medium } \\
\text { adherence }\end{array}$ & $\begin{array}{c}\text { Low } \\
\text { adherence }\end{array}$ & \multirow{2}{*}{ Total } & \multirow{2}{*}{ p value } \\
\hline \multirow{2}{*}{ Sex } & Male & $30(37.5 \%)$ & $37(46.2 \%)$ & $13(16.2 \%)$ & $80(100 \%)$ & \multirow{2}{*}{0.008} \\
\cline { 2 - 6 } & Female & $55(61.1 \%)$ & $27(30 \%)$ & $8(8.9 \%)$ & $90(100 \%)$ & \\
\hline \multirow{3}{*}{$\begin{array}{c}\text { Age } \\
\text { years })\end{array}$} & $35-45$ & $8(44.4 \%)$ & $7(38.9 \%)$ & $3(16.7 \%)$ & $18(100 \%)$ & \multirow{2}{*}{0.951} \\
\cline { 2 - 6 } & $46-55$ & $15(48.4 \%)$ & $13(41.9 \%)$ & $3(9.7 \%)$ & $31(100 \%)$ & \\
\cline { 2 - 6 } & $56-65$ & $34(54.8 \%)$ & $22(35.5 \%)$ & $6(9.7 \%)$ & $62(100 \%)$ & \\
\cline { 2 - 6 } & $66-75$ & $21(51.2 \%)$ & $14(34.1 \%)$ & $6(14.6 \%)$ & $41(100 \%)$ & \\
\cline { 2 - 6 } & $>75$ & $7(38.9 \%)$ & $8(44.4 \%)$ & $3(16.7 \%)$ & $18(100 \%)$ & \\
\hline
\end{tabular}

Table 4: Comparison of employment status and education factors with extent of adherence (n=170)

\begin{tabular}{|l|l|c|l|l|l|l|}
\hline Variable & $\begin{array}{l}\text { High } \\
\text { adherence }\end{array}$ & Medium & Low & Total & \multirow{2}{*}{ p value } \\
\hline \multirow{3}{*}{$\begin{array}{l}\text { Employment } \\
\text { Status }\end{array}$} & Government & 0 & $1(100 \%)$ & 0 & $1(100 \%)$ & \multirow{2}{*}{0.014} \\
\cline { 2 - 6 } & Merchant & $14(36.8 \%)$ & $19(50 \%)$ & $5(13.2 \%)$ & $38(100 \%)$ & \\
\cline { 2 - 6 } & Housewife & $36(70.6 \%)$ & $14(27.4 \%)$ & $1(20 \%)$ & $51(100 \%)$ & \\
\cline { 2 - 6 } & Farmer & $16(40 \%)$ & $15(37.5 \%)$ & $9(22.5 \%)$ & $40(100 \%)$ & \\
\cline { 2 - 6 } & Retired & $19(47.5 \%)$ & $15(37.5 \%)$ & $6(15 \%)$ & $40(100 \%)$ & \multirow{2}{*}{0.868} \\
\hline \multirow{2}{*}{ Education } & Illiterate & $64(53.8 \%)$ & $41(34.5 \%)$ & $14(11.7 \%)$ & $119(100 \%)$ & \\
\cline { 2 - 6 } & Literate & $21(42 \%)$ & $23(46 \%)$ & $7(14 \%)$ & $51(11.7 \%)$ & \\
\hline
\end{tabular}

Table 5: Comparison of socio economic status and marital status with extent of adherence ( $n=170)$

\begin{tabular}{|l|l|c|c|c|c|c|}
\hline \multicolumn{2}{|c|}{ Variable } & $\begin{array}{c}\text { High } \\
\text { adherence }\end{array}$ & $\begin{array}{c}\text { Medium } \\
\text { adherence }\end{array}$ & $\begin{array}{c}\text { Low } \\
\text { adherence }\end{array}$ & Total & \multirow{2}{*}{ p value } \\
\hline \multirow{2}{*}{$\begin{array}{l}\text { Socio } \\
\text { economic } \\
\text { status }\end{array}$} & Upper & - & - & - & - & \multirow{2}{*}{0.601} \\
\cline { 2 - 6 } & Upper middle & $2(66.7 \%)$ & $1(33.3 \%)$ & 0 & $3(100 \%)$ & \\
\cline { 2 - 6 } & Middle & $9(56.2 \%)$ & $5(31.2 \%)$ & $2(12.5 \%)$ & $16(100 \%)$ & \\
\cline { 2 - 6 } & Lower middle & $50(45.9 \%)$ & $42(38.5 \%)$ & $17(15.6 \%)$ & $109(100 \%)$ & \\
\cline { 2 - 6 } & Lower & $24(57.1 \%)$ & $16(38.1 \%)$ & $2(4.8 \%)$ & $42(100 \%)$ & \\
\hline \multirow{3}{*}{$\begin{array}{l}\text { Marital } \\
\text { status }\end{array}$} & Single & $1(33.3 \%)$ & $2(66.7 \%)$ & 0 & $3(100 \%)$ & \multirow{2}{*}{0.443} \\
\cline { 2 - 6 } & Married & $62(48.1 \%)$ & $52(40.3 \%)$ & $15(11.6 \%)$ & $129(100 \%)$ & \\
\cline { 2 - 6 } & Divorced & - & - & - & 0 & \\
\cline { 2 - 6 } & Widowed & $22(57.9 \%)$ & $10(26.3 \%)$ & $6(15.8 \%)$ & $38(100 \%)$ & \\
\hline
\end{tabular}

Table 6: Comparison of religion and distance from RHTC with extent of adherence (n=170)

\begin{tabular}{|l|c|c|c|c|c|c|}
\hline \multicolumn{2}{|c|}{ Variable } & $\begin{array}{c}\text { High } \\
\text { adherence }\end{array}$ & $\begin{array}{c}\text { Medium } \\
\text { adherence }\end{array}$ & $\begin{array}{c}\text { Low } \\
\text { adherence }\end{array}$ & Total & \multirow{2}{*}{ p value } \\
\hline \multirow{3}{*}{ Religion } & Hindu & $81(51.9 \%)$ & $56(35.9 \%)$ & $156(100 \%)$ & $156(100 \%)$ & \multirow{2}{*}{0.001} \\
\cline { 2 - 6 } & Muslim & $4(33.3 \%)$ & $8(66.7 \%)$ & $12(100 \%)$ & $12(100 \%)$ & \\
\cline { 2 - 6 } & Christian & 0 & 0 & $2(100 \%)$ & $2(100 \%)$ & \\
\cline { 2 - 6 } & Others & - & - & - & - & \\
\cline { 1 - 6 } $\begin{array}{l}\text { Time to reach } \\
\text { RHTC }\end{array}$ & $<0.5 \mathrm{hr}$ & $41(54.7 \%)$ & $31(41.3 \%)$ & $75(100 \%)$ & $75(100 \%)$ & \multirow{2}{*}{0.013} \\
\cline { 2 - 6 } & $>0.5 \mathrm{hr}$ & $44(46.3 \%)$ & $33(34.7 \%)$ & $95(100 \%)$ & $95(100 \%)$ & \\
\hline
\end{tabular}


Table 7: Association of risk factors with adherence $(n=170)$

\begin{tabular}{|l|c|c|c|c|c|c|}
\hline \multicolumn{2}{|c|}{ Variable } & $\begin{array}{c}\text { High } \\
\text { adherence }\end{array}$ & $\begin{array}{c}\text { Medium } \\
\text { adherence }\end{array}$ & $\begin{array}{c}\text { Low } \\
\text { adherence }\end{array}$ & Total & p value \\
\hline \multirow{2}{*}{ Comorbidities } & Present & $30(56.5 \%)$ & $19(35.8 \%)$ & $4(7.5 \%)$ & $53(100 \%)$ & \multirow{2}{*}{0.337} \\
\cline { 2 - 6 } & Absent & $55(47 \%)$ & $45(38.5 \%)$ & $17(14.5 \%)$ & $117(100 \%)$ & \\
\hline Familial H/o & Present & $11(50 \%)$ & $6(27.3 \%)$ & $5(22.7 \%)$ & $22(100 \%)$ & \multirow{2}{*}{0.232} \\
\cline { 2 - 6 } & Absent & $74(50 \%)$ & $58(39.2 \%)$ & $16(10.8 \%)$ & $148(100 \%)$ & \\
\hline \multirow{2}{*}{$\begin{array}{l}\text { Smoking/tobacco } \\
\text { chewing }\end{array}$} & Present & $13(56.5 \%)$ & $8(34.8 \%)$ & $2(8.7 \%)$ & $23(100 \%)$ & \multirow{2}{*}{0.751} \\
\cline { 2 - 6 } $\begin{array}{l}\text { Alcohol } \\
\text { Addiction }\end{array}$ & Absent & $72(49 \%)$ & $56(38.1 \%)$ & $19(12.9 \%)$ & $147(100 \%)$ & \\
\cline { 2 - 6 } & Present & $17(48.6 \%)$ & $12(34.3 \%)$ & $6(17.1 \%)$ & $35(100 \%)$ & \multirow{2}{*}{0.616} \\
\hline
\end{tabular}

\section{Discussion}

This study was an institutional based cross sectional study conducted between november 2017 to march 2018. Current study shows that $53 \%$ of study population were females, majority belong to 56-65 years $(36.4 \%)$ of age group and were housewives $(30 \%)$. Majority of study population were illiterates (70\%), belong to lower middle socio economic status $(64.2 \%)$, were $\operatorname{married}(75.8 \%)$ and were hindus( $(91.7 \%)$. Majority of study population were staying $>0.5 \mathrm{KM}$ from the RHTC $(55.9 \%)$. Similar results were observed in the study conducted by Khwaja $\mathrm{M}$ et $\mathrm{al}^{7}$ that majority were males, hindus, married, illiterates.

Only $50 \%$ of the study subjects were found to be adherent to their treatment. Similar results were observed in the study conducted in by Shruti $\mathrm{R}$ et $\mathrm{al}^{8}$ where the adherence was $45.41 \%$. Current study results were lower when compared to the observation of Ambaw $\mathrm{AD}$ et $\mathrm{al}^{5}$ study in which $64.6 \%$ of study population were adherent and in Hashmi SK et $\mathrm{al}^{1}$ study which showed adherence among $77 \%$ of study population. This is probably because of the difference in study setting and variations in assessment tool for adherence. Contradictory results were observed in Khwaja $\mathrm{M}$ et $\mathrm{al}^{7}$ study in which $23.7 \%$ of study population showed medium adherence.

In the current study it was observed that sex, employment status, religion and distance from RHTC were significantly associated with the adherence to treatment. People living far away from the health centre found it difficult to adhere to the medication, even though it was offered free may be because of the long distance which delayed them from coming for regular follow up and regular refill of medication when they got over.

In the study conducted by Ambaw $\mathrm{AD}$ et $\mathrm{al}^{5}$, significant association was found between adherence and sex, time taken to travel is $<0.5 \mathrm{~h}$ from the hospital, having no or one co-morbidity, having controlled BP, being knowledgeable about HTN. Similar results were observed in the study conducted by the Inkster ME et $\mathrm{al}^{9}$ that distance from the hospital was another variable found to be significantly with adherence.
In a study done by Rao CR et $\mathrm{al}^{2}{ }^{2}$ age was a variable which had significance with adherence and they described that most of the elderly may have difficulty in remembering to take medication regularly. With increased age, they might have co morbid conditions for which they might be taking medications so that might lead to confusion and thereby decreased adherence. Compliance to hypertension treatment was better among females as compared to males and this difference was noted to be statistically significant.

In the studies conducted by Sweileh WM et al, ${ }^{10}$ Al-Mehza AM et $\mathrm{al}^{11}$ and Kumar PN et al ${ }^{12}$ women were found to be more compliant to treatment than men which is similar to the findings of our study. In another study done by Shruthi $\mathrm{R}$ et $\mathrm{al},{ }^{8}$ educational status was found to be significant. With better education comes better knowledge and better attitude towards disease.

In the current study, study population with the comorbities $(56.5 \%)$, with habits like smoking and tobacco chewing $(56.5 \%)$ were more adherent. People without alcohol consumption were more adherent (50.4\%) and persons with both familial history and no familial history have same adherence. These differences were statistically not significant. This can be explained by the fact men can be subject to addictions like alcohol and heavy manual labour which can lead to non adherence. Contradictory results were observed in the study conducted by Khwaja $\mathrm{M}$ et $\mathrm{al}^{7}$ and Shruthi $\mathrm{R}$ et $\mathrm{al}^{8}$ comordities significantly associated with adherence. In the study conducted by Oliveira $\mathrm{AD}$ et al ${ }^{13}$ it was found that nonsmokers (23\%) and nonalcoholics $(21.3 \%)$ were more adherent.

\section{Conclusion}

Only half of the study subjects were found to be adherent to their treatment. In the current study it was observed that sex, employment status, religion and distance from RHTC were significantly associated with the adherence to treatment. Study population with the comorbidties, with habits like smoking and tobacco chewing were more adherent. People without alcohol consumption were more adherent and persons with both familial history and no familial history have same adherence. These differences were statistically not significant. 


\section{References}

1. Hashmi SK, Afridi MB, Abbas K, Sajwani RA, Saleheen D, et al. Factors Associated with Adherence to AntiHypertensive Treatment in Pakistan. PLoS ONE 2007;2(3):280-88.

2. Rao CR, Kamath VG, Shetty A, Kamath A. Treatment Compliance among Patients with Hypertension and Type 2 Diabetes Mellitus in a Coastal Population of Southern India. Int J Prev Med. 2014;5(8):992-98.

3. World Health Organisation. Health topics: Cardiovascular disease. Available at: http://www.who.int/cardiovascular_diseases/en/. Accessed on 24 march 2018

4. International Institute for Population Sciences (IIPS) and ICF. 2017. National Family Health Survey (NFHS-4), 2015-16: India. Mumbai: IIPS. Available at http://rchiips.org/nfhs/NFHS-4Reports/India.pdf / Accessed on 23 march 2018

5. Ambaw AD, Alemie GA, Yohannes SMW, Mengesha $\mathrm{ZB}$. Adherence to antihypertensive treatment and associated factors among patients on follow up at University of Gondar Hospital, Northwest Ethiopia. BMC Public Health 2012;12:282-87

6. Morisky DE, Green LW, Levine DM. Concurrent and predictive validity of a self-reported measure of medication adherence. Med Care.1986;24:67-74.

7. Khwaja M, Ansari MA, Mehnaz S. Compliance to antihypertensive medication: a cross-sectional study in Aligarh. Int J Community Med Public Health 2017;4:3698-704

8. Shruthi R, Jyothi R, Pundarikaksha HP, Nagesh GN, Tushar TJ. A Study of Medication Compliance in Geriatric Patients with Chronic Illnesses at a Tertiary Care Hospital. Journal of Clinical and Diagnostic Research. 2016;10(12): 40-43

9. Inkster ME, Donnan PT, MacDonald TM, Sullivan FM, Fahey T. Adherence to antihypertensive medication and association with patient and practice factors. J Hum Hypertens 2006, 20(4):295-97.

10. Sweileh WM, Aker O, Hamooz S. Rate of compliance among patients with diabetes mellitus and hypertension. An-Najah Univ J Research-A-(Natural Sciences) 2005;19:1-12.

11. Al-Mehza AM, Al-Muhailije FA, Khalfan MM, AlYahya AA. Drug compliance among hypertensive patients; an area based study. Eur J Genet Med. 2009;6:6-10.

12. Kumar PN, Halesh LH. Antihypertensive treatment: A study on correlates of non adherence in a tertiary care facility. Int J Biol Med Res. 2010;1:248-52.

13. Oliveira-Filho AD, Barreto-Filho JA, Neves SJF. Association between the 8-item Morisky Medication Adherence Scale (MMAS-8) and Blood Pressure Control. Arq Bras Cardiol. 2012; 99(1):649-58. 